\title{
DIAGNÓSTICO SOBRE A SATISFAÇÃO DOS USUÁRIOS DE TECNOLOGIAS DE INFORMAÇÃO E COMUNICAÇÃO (TIC) NA UNIVERSIDADE FEDERAL DE JATAII
}

\author{
Ana Paula Freitas Vilela-Boaventura ${ }^{1}$ \\ Ana Amélia Freitas-Vilela ${ }^{2}$
}

Resumo: As Tecnologias de Informação e Comunicação (TIC) são recursos didáticos constituídos por diferentes mídias e tecnologias, síncronas e assíncronas. Atualmente o uso das TIC em todos os setores da sociedade, particularmente na educação formal e informal são essenciais. Sendo assim, o objetivo deste estudo foi investigar a percepção dos usuários da TIC dentro da instituição, sobre a qualidade dos equipamentos e a relação satisfatória sobre a demanda. Face a emancipação da Universidade Federal de Jataí (UFJ), proveniente do desmembramento da Universidade Federal de Goiás / Regional Jataí (UFG/ REJ) fez-se um estudo descritivo sobre a percepção dos usuários da TIC dentro da instituição. Em termos metodológicos, um questionário elaborado seguindo os documentos norteadores foi enviado à comunidade acadêmica interna e externa. Os resultados obtidos mostram insatisfação dos participantes. Entre os recursos e/ou equipamentos mais solicitados estavam o datashow, internet de boa qualidade e salas equipadas com central de multimídia.

Palavras chaves: Diagnóstico; Tecnologias de Informação e Comunicação; Ensino.

\footnotetext{
${ }^{1}$ Unidade Acadêmica Especial de Ciências Exatas e Tecnológicas, Curso Ciências da Computação, Universidade Federal de Jataí, Jataí-GO, Brasil. apfvboaventura@gmail.com

${ }^{2}$ Unidade Acadêmica Especial de Ciências da Saúde, Curso Medicina, Universidade Federal de Jataí, Jataí-GO, Brasil.anaameliafv@gmail.com
} 


\title{
DIAGNOSIS ON THE SATISFACTION OF USERS OF COMMUNICATION AND INFORMATION TECHNOLOGIES (CIT) IN THE FEDERAL UNIVERSITY OF JATAÍ
}

\begin{abstract}
Communication and Information and Technologies (CIT) are didactic resources made up of different media and technologies, synchronous and asynchronous. The use of CIT is essential in all sectors of society, particularly in formal and informal education. This way, the aim of this study was to investigate the perception of CIT users of institution, about the quality of the equipment and the satisfactory relation on the demand. Faced the emancipation of the Federal University of Jataí (UFJ), specializing in teaching at the Federal University of Goiás / Jataí Regional (UFG / REJ, Portuguese acronym). In methodological terms, a questionnaire elaborated under the guiding documents was submitted to the international and external academic community. The results may be dissatisfaction of the participants.The results show that there is relation between the physical structure and the CIT, which impacted negatively the satisfaction of the participants. Among the most requested features and / or equipment were the Datashow, better internet quality and rooms equipped with multimedia center.
\end{abstract}

Key words: Diagnosis; Communication and information technologies; Education. 


\section{INTRODUÇÃO}

As Tecnologias de Informação e Comunicação (TIC) são recursos didáticos constituídos por diferentes mídias e tecnologias, síncronas e assíncronas, como por exemplo, Ambientes Virtuais de Aprendizagem (AVA), redes sociais, fórum, chat, mídia impressa, áudio, vídeo, imagem e hipermídia. A sigla TIC, por sua vez, possui um contexto mais abrangente e pode ser entendida como as Tecnologias Digitais de Informática e de Redes de Troca de Dados (TICS), enfatizando o uso da web, interligando pessoas distribuídas geograficamente (MIRANDA, 2007; LITTO e FORMIGA, 2009; NUNES, et al., 2015).

Atualmente o uso das TIC em todos os setores da sociedade, particularmente na educação formal e informal são essenciais. Os avanços tecnológicos permitem que o processo de ensino-aprendizagem e de formação geral dos discentes, foram amplamente incluídos nas práticas dos docentes e discentes de todas as áreas e não apenas àquelas relacionadas à tecnologia e informática. Nos anos 80 e início de 90 a informática teve a disseminação acelerada no sistema educacional, com a iniciativa do Ministério da Educação - MEC (MIRANDA, 2007; STURION et al., 2011).

$\mathrm{O}$ uso das TIC possibilita uma maior autonomia para o discente para aprimorar seus conhecimentos, uma vez que ele passa de mero expectador e receptor de informações para construtor de seu conhecimento e os professores e técnicos passam a ser tutores de conhecimentos, deixando de ser apenas transmissores para serem mediadores do processo de construção do conhecimento. O emprego das TIC está cada vez mais presente no ensino superior, uma vez que atualmente há cursos que são na modalidade de ensino à distância (EaD) e cursos presenciais com carga horária EaD (STURION et al., 2011; NUNES, et al., 2015).

Com o aumento da tecnologia na processo ensino-aprendizagem, os AVA são importantes ferramentas a serem utilizadas para aprimorar a qualidade do ensino, seja ela semi-presencial ou totalmente a distância, otimizando processos de interação e colaboração. Moodle, TelEduc e Tidia-Ae são algumas das ferramentas integrantes dos AVA, os quais são plataformas virtuais que reúnem funcionalidades que possibilitam interações online entre os atores do processo de ensino aprendizagem no que tange às atividades do curso, (FRANCISCATO et al., 2008; NUNES, et al., 2015).

O emprego de TIC aprimora a interação entre os indivíduos e consequentemente, promove maior fluidez na difusão do conhecimento. Assim sendo, o objetivo do presente estudo foi investigar a percepção dos usuários da TIC dentro da instituição, sobre a qualidade 
dos equipamentos e a relação satisfatória sobre a demanda, para enfim, traçar estratégias que permitam melhorar o uso de tais dispositivos na Universidade Federal de Goiás/Regional Jataí (UFG/ Regional Jataí).

No artigo “ RELATO DA METODOLOGIA GERAL DE ESTUDO DO DIAGNÓSTICO DO ENSINO DE GRADUAÇÃO (Benite-Ribeiro \& Inocêncio), do presente Diagnóstico do Ensino da REJ, está elencada a metodologia do trabalho, bem como a identificação da amostra e o protocolo do CEP. Os resultados e a discussão são apresentados na seção 3, a conclusão na seção 4 e por fim a seção 5 das referências bibliográficas.

\section{MATERIAIS E MÉTODOS}

Este estudo foi motivado pela iminente emancipação da Universidade Federal de Jataí, proveniente do desmembramento da UFG / Regional Jataí. Para tanto foram formadas comissões que tinham por objetivo identificar quantitativamente e/ou qualitativamente a situação institucional em diferentes dimensões, como ensino, pesquisa, extensão entre outros. No que diz respeito ao ensino, criou-se o Grupo de Trabalho de Ensino, no qual era subdivido em diferentes frentes. Especificamente, este trabalho é resultado da pesquisa realizada pelo Subgrupo de trabalho - TIC, em que fez um estudo descritivo com os membros da comunidade acadêmica (docente, discentes e técnico-administrativos em educação (TAE)) e comunidade externa (egressos da instituição e/ou aposentados).

Para atingir o maior número de usuários foi elaborado um formulário online pela equipe responsável pelo estudo, o qual foi enviado para toda a comunidade acadêmica e externa que têm os e-mails cadastrados na Assessoria de Comunicação da Regional Jataí da Universidade Federal de Goiás (ASCOM UFG). O período de coleta de dados ocorreu entre os dias 8 a 18 de maio de 2018.

O formulário enviado aos usuários de TIC foi elaborado pela equipe e continha os seguintes temas:

- Verificação do conhecimento dos usuários das TIC sobre os conceitos das mesmas;

- Identificação das ferramentas midiáticas utilizadas na Instituição de Ensino Superior (IES);

- Destaque sobre a importância das ferramentas no contexto pedagógico;

- Verificação da percepção dos usuários quanto ao uso do Sistema Integrado de Gestão de Atividades Acadêmicas (SIGAA) nas atividades de ensino e pesquisa; 
- Aferição da influência das TIC no que tange ao nivelamento, acessibilidade e atividades extraclasse;

- Investigação da relação entre as atividades de tutoria vs. TIC;

- Levantamento da infraestrutura das TIC em salas de aula e laboratórios;

- Verificação do controle e distribuição de materiais institucionais.

Os dados obtidos foram tabulados e foi realizada análise descritiva, como média e desvio padrão, quando aplicável. Todas as análises foram realizadas no Microsoft Office Excel . $^{\oplus}$

Todos os participantes tinham idade superior a 18 anos e assinaram o Termo de Consentimento Livre e Esclarecido (TCLE), seguindo-se a Resolução do Conselho Nacional de Ética em Pesquisa (CONEP) n. ${ }^{\circ}$ 196, de 1996, e n. ${ }^{\circ}$ 251, de 1997, sobre Diretrizes e Normas Regulamentadoras para pesquisas em seres humanos, do Ministério da Saúde. Os resultados foram apresentados em grupo, de modo a não identificar cada sujeito (BRASIL, 1996).

\section{RESULTADOS E DISCUSSÃO}

Atualmente, a UFG/Regional Jataí possui 25 cursos de graduação, 5 programas de mestrado e 1 de doutorado, que são divididos em 8 Unidades Acadêmicas, conforme consta no Quadro 1.

Quadro 1: Descrição das Unidades Acadêmicas e os respectivos cursos de graduação e pósgraduação

\begin{tabular}{|c|c|}
\hline $\begin{array}{l}\text { Unidade Acadêmica } \\
\text { Especial }\end{array}$ & Cursos \\
\hline $\begin{array}{l}\text { Ciências } \quad \text { Agrárias } \\
\text { CIAGRA }\end{array}$ & $\begin{array}{l}\text { Agronomia, Engenharia Florestal, Medicina Veterinária, Zootecnia e } \\
\text { Mestrado em Agronomia }\end{array}$ \\
\hline Biociência - CIBIO & Ciências Biológicas (Bacharelado e Licenciatura) \\
\hline $\begin{array}{l}\text { Ciências } \quad \text { Exatas } \\
\text { Tecnológicas }\end{array}$ & $\begin{array}{l}\text { Ciências da Computação, Física (Licenciatura), Matemática, Química } \\
\text { (Bacharelado e Licenciatura) e Mestrado Profissional em Matemática }\end{array}$ \\
\hline Educação - EDUC & Pedagogia (Licenciatura) e Mestrado Profissional em Educação \\
\hline $\begin{array}{l}\text { Ciências Humanas e Letras - } \\
\text { CHL }\end{array}$ & $\begin{array}{l}\text { História (Licenciatura), Letras (Licenciatura em Inglês e em } \\
\text { Português) e Psicologia (Licenciatura e Bacharelado) }\end{array}$ \\
\hline $\begin{array}{l}\text { Ciências Sociais Aplicadas - } \\
\text { CSociais }\end{array}$ & Direito (Bacharelado) \\
\hline Estudos Geográficos & $\begin{array}{l}\text { Geografia (Bacharelado e Licenciatura), Mestrado em Geografia, } \\
\text { Doutorado em Geografia }\end{array}$ \\
\hline
\end{tabular}


Ciências da Saúde - CISAU Biomedicina, Educação Física (Bacharelado e Licenciatura), Enfermagem, Fisioterapia, Medicina e Mestrado em Ciências Aplicadas à Saúde

No presente estudo foram avaliados 46 indivíduos da comunidade acadêmica e externa, sendo $29(63,0 \%)$ de docentes, $3(6,5 \%)$ de TAE, $13(28,3 \%)$ de discentes e $1(2,2 \%)$ de comunidade externa. A idade mínima dos entrevistados foi 18 e a máxima 58, a idade média e o desvio-padrão da população avaliada foi 34,16 e 7,83 anos, respectivamente. A Figura 1 apresenta a relação de entrevistados por unidade acadêmica e/ou setor.

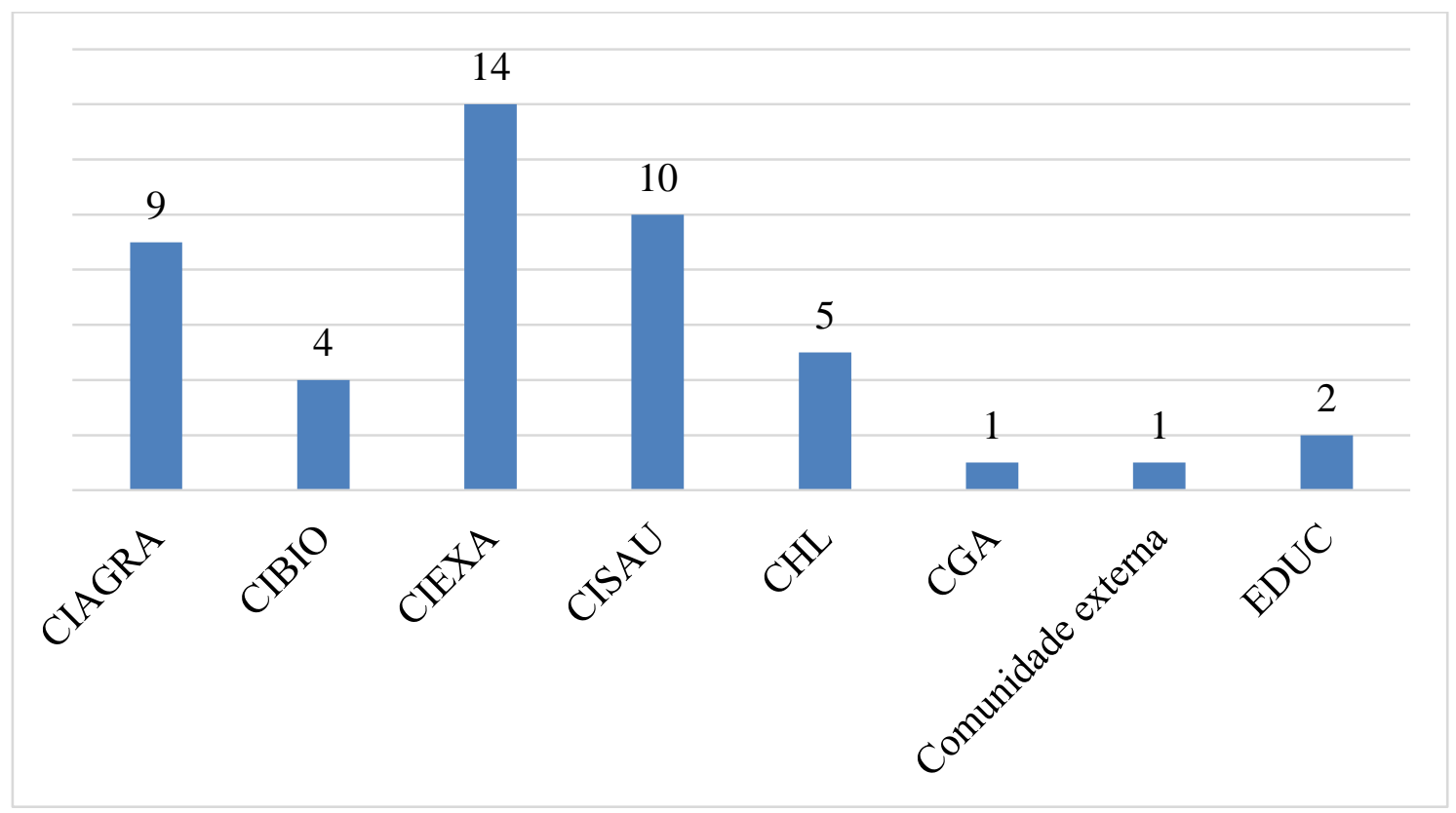

Figura 1. Relação da quantidade de pessoas que responderam ao questionário por unidade acadêmica e /ou setor. CIAGRA: Unidade Acadêmica Especial de Ciências Agrárias Jataí; CIBIO: Unidade Acadêmica Especial de Biociência; CIEXA: Unidade Acadêmica Especial de Ciências Exatas e Tecnológica; CISAU: Unidade Acadêmica Especial de Ciências da Saúde; CHL: Unidade Acadêmica Especial de Ciências Humanas e Letras; CGA: Centro de Gestão Acadêmica; EDUC Unidade Acadêmica Especial de Educação.

Quando questionados sobre o tipo de recurso mais utilizado disponibilizado pela UFGREJ, a quantidade de indivíduos que responderam (indicado pela variável n), observou-se que as mídias escritas e vídeos são os mais utilizados para o processo de ensino aprendizagem, como o livro $(97,8 \%, n=45)$, data show $(97,8 \%, n=45)$ e lousa e giz $(93,5 \%, n=43)$. A internet $(87,0 \%, n=40)$ e a xerox $(76,1, n=35)$ foram classificados como medianos, enquanto vídeo aulas $(15,2 \%, \mathrm{n}=7)$ e áudios das aulas $(4,3 \%, \mathrm{n}=2)$ apresentam baixa disponibilidade pela universidade.

Conforme ressaltado pelos instrumentos norteadores, os AVA são muito importantes para a comunicação entre os pares. Assim, a primeira pergunta neste sentido, investigava 
como o usuário avalia o SIGAA. A maioria dos entrevistados $(32,6 \%)$ o avalia como "muito bom" e a minoria classificou como "péssimo" (4,3\%) (Figura 2). O desenvolvimento e a implementação dos ambientes virtuais de aprendizagem apresentam desafios em relação à configuração de um ambiente de aprendizagem, à construção de um sistema tendo em mente um usuário-prototípico, ao padrão de uso do sistema e às necessidades dos usuários atuais ou para situações de aprendizagem (LAGUARDIA et al., 2007).

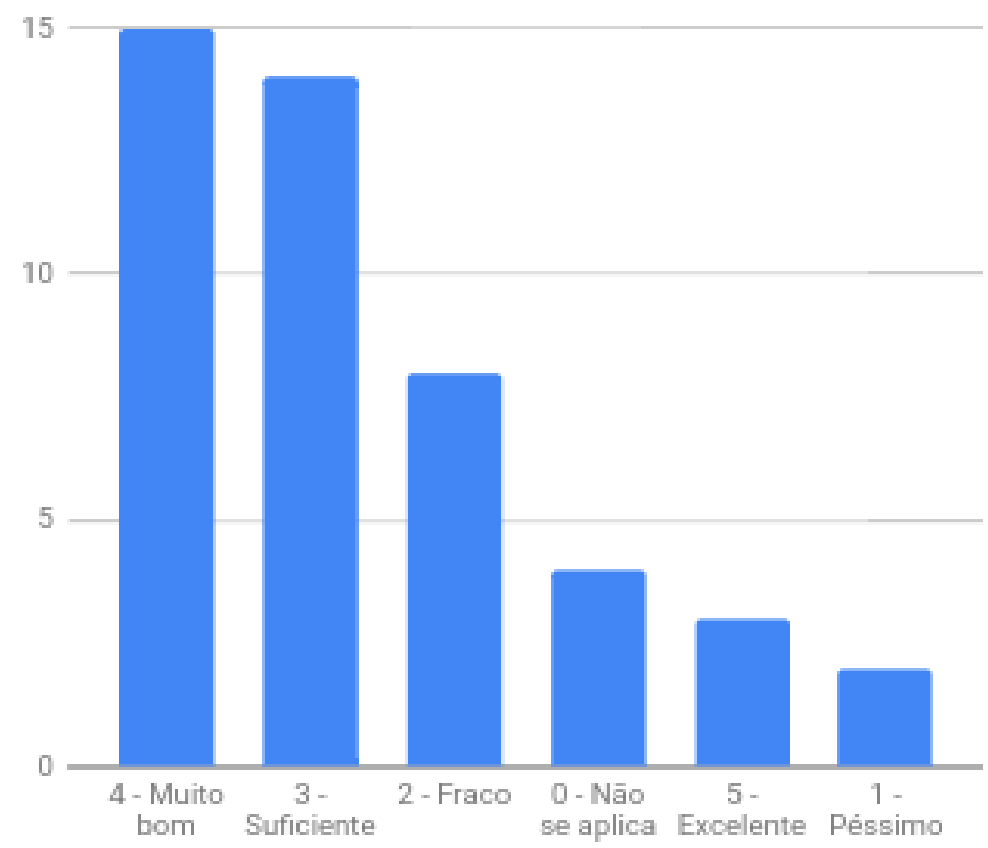

Figura 2. Avaliação do SIGAA pelos usuários.

Sobre o uso das TIC no auxílio ao apoio extraclasse e psicopedagógico no que diz respeito à acessibilidade, nivelamento e atividades extracurriculares. Sobre a acessibilidade, $34,8 \%$ julgaram como "insuficiente", contra 15,2\% "muito bom" e 30,4\% "suficiente". No que tange ao nivelamento 51,1\% assinalaram como "insuficiente", contra 8,9\% "muito bom" e $20,9 \%$ "suficiente", no entanto $15,6 \%$ disseram que tal recurso é "inexistente". Por fim, no quesito atividades extracurriculares $56,5 \%$ avaliaram como insuficiente, contrastando com $23,9 \%$ como "suficiente" e 8,7\% como "muito bom".

Os AVA são essenciais para o processo ensino-aprendizagem mediadas por TIC, pois permitem integrar diferentes mídias, linguagens e recursos, as quais serão apresentadas de maneira organizada e desenvolvem interações entre pessoas e objetos do conhecimento. Por meio do AVA é possível interações entre docente, discente e monitores propiciando trocas 
individuais e a formação de grupos colaborativos onde os participantes discutem sobre o tema proposto pelo docente, ampliando e compartilhando o conhecimento de quem utiliza esse sistema. Neste contexto, o ator principal das atividades em AVA é o discente, estabelecendo interações com seus pares e docente (ALMEIDA, 2001; NUNES, et al., 2015).

A maioria dos cursos da UFG/Regional Jataí não apresentam a modalidade EaD, desta forma, 39,1\% usuários disseram que "Não se aplica" quando questionados se a tutoria atendia às demandas didático-pedagógicas das estruturas curricular, no entanto 19,6\% acreditam ser "insuficiente", 17,4\% "suficiente" e 15,2\% "não existe". No quesito que averiguava se as TIC permitem interação entre docentes, tutores e estudantes da IES 28,3\% opinaram como "Não se aplica", mas 28,3\% consideram "insuficiente", 26,1\% suficiente e 15,2\% muito bom. A realidade de tutoria é cada vez mais crescente no Brasil, com o aumento do ensino superior $\mathrm{EaD}$ e presencial com parte da carga horaria EaD. Essas mudanças nos processos de trabalho que exigem o um processo de inovação educacional mais amplo que é a integração das novas tecnologias de informação e comunicação nos processos educacionais (LAGUARDIA et al., 2007).

Em relação ao material didático institucional disponibilizado aos discentes permite aos mesmos executarem formação definida pelo Projeto Pedagógico do Curso (PPC), 47,8\% concordaram de que foi "insuficiente", enquanto 21,7\% dizem ser "suficiente". Para $64,4 \%$ os laboratórios de informática especializados atendem de forma "insuficiente" às necessidades pedagógicas da comunidade acadêmica e civil, semelhante aos laboratórios especializados possuem recursos TIC que atendam às necessidades, que para 57,8\% foi "insuficiente".

A falta de material didático relacionados aos laboratórios de informática e insatisfação com os laboratórios de informática especializados pode ser explicado pelo número reduzido de computadores disponíveis para os cursos de graduação e principalmente pela qualidade da internet disponibilizada para a universidade, uma vez que impossibilita de desenvolver atividades em AVA. Segundo Miranda (2007), as pessoas que trabalham no domínio da Tecnologia Educativa se interessam pelos recursos e avanços técnicos, contribuindo para o melhor processo de ensino-aprendizagem, sendo o computador e a internet os principais recursos técnicos para desenvolver esse procedimento. Uma vez que tais recursos são escassos, podem contribuir negativamente para o desenvolvimento das aulas $\mathrm{e}$ consequentemente ter uma avaliação negativa pelos usuários.

Por fim, foi questionado a avaliação do usuário sobre a estrutura do UFG/ Regional Jataí e mais da metade da comunidade (52,2\%) consideram "fraca" e 30,4\% "suficiente". Em 
relação as sugestões de melhoria, 33 participantes deram sua opinião, mas nem todas foram relacionadas a TIC. Alguns participantes solicitaram melhorias na estrutura física, como pisos, salas de aulas, cadeiras, mesas entre outros, no entanto o objetivo da enquete foi avaliar quais eram as solicitações da comunidade acadêmica para melhorar a qualidade dos serviços relacionados às TIC. Desta forma as respostas, relacionadas à TIC, foram organizadas e aquelas que foram mencionadas mais de uma vez, foram apresentadas apenas uma vez:

- Ampliação de espaços físicos, adequação da velocidade e suporte da rede de dados;

- Melhoria da rede de internet e telefonia do campus Jatobá e Riachuelo;

- Disponibilidade de Datashow e internet nas salas de aula;

- Auditório com recursos que permitam videoconferência;

- Aumento do número de laboratórios de informática multiusuário;

- Suporte à Informação (mídias, internet, computadores e projetores);

- Instalação elétrica satisfatória (fiação, tomadas, disjuntores, entre outros);

- Ampliação dos horários de atendimento que permitam o acesso a todo público (matutino, vespertino e noturno);

- Melhorar a infraestrutura dos laboratórios didáticos, com maior disponibilidade de equipamentos e material para aulas práticas, permitindo melhor interface entre TICs e prática;

- Reposição de giz e pincel;

- Construir uma política de modernização/implantação de sistemas/redes que possibilitem o desenvolvimento de atividades a distância/presenciais, no que tange ao aspecto ensino/pesquisa;

- Capacitação dos professores relacionadas às atividades em AVA.

\section{CONSIDERAÇÕES FINAIS}

No presente estudo, foi possível observar uma estreita relação entre a estrutura física e às TIC, impactando negativamente na satisfação dos participantes. Dentre os recursos e/ou equipamentos mais solicitados estão o Datashow, internet de boa qualidade e salas equipadas com central de multimídia. O uso dos AVA é uma ferramenta que pode facilitar no processo ensino-aprendizagem, desta forma, atividades educativas sobre a plataforma utilizada na Regional Jataí devem ser incentivadas e realizadas para aprimorar as práticas no AVA. A adesão da comunidade acadêmica foi muito baixa, mas mesmo com um número baixo de usuários foi possível fazer um diagnóstico da situação atual da UFG/ Regional Jataí. Diante 
do exposto, foi possível avaliar a situação atual do UFG-REJ e quais são os itens prioritários de melhoria para que tenhamos uma UFG/ Regional Jataí de qualidade para docentes, discentes, TAE e comunidade externa, que esporadicamente ainda realizam atividades no espaço físico da instituição.

\section{REFERÊNCIAS BIBLIOGRÁFICAS}

ALMEIDA, M.E.B. "Formando professores para atuar em ambientes virtuais de aprendizagem.” In: ALMEIDA, F. J. (Coord). Projeto Nave. Educação a distância: formação de professores em ambientes virtuais e colaborativos de aprendizagem. São Paulo: [s.n.], 2001.

BRASIL. Ministério da Saúde. Conselho Nacional de Saúde. Diretrizes e normas regulamentadoras sobre pesquisa envolvendo seres humanos. Resolução 196. 1996. Brasília: CNS; 1996.

FRANCISCATO, F.T; RIBEIRO, P.S.; MOZZAQUATRO, P.M; MEDINA, R.D. Avaliação dos Ambientes Virtuais de Aprendizagem Moodle, TelEduc e Tidia - Ae: um estudo comparativo. Novas Tecnologias na Educação. V. 6 N² 2, Dezembro, 2008.

LAGUARDIA, J.; PORTELA, M.C.; VASCONCELLOS, M.M. Avaliação em ambientes virtuais de aprendizagem. Educação e Pesquisa, São Paulo, v.33, n.3, p. 513-530, set./dez. 2007.

MIRANDA, G.L. Limites e possibilidades das TIC na educação. sísifo/Revista de Ciências da Educação n. ${ }^{\circ} 3$ mai/ago. 2007.

NUNES, C.S.; TORRES, M.K.L.; OLIVEIRA, P.C.; NAKAYAMA, M.K. Aprendizagem Organizacional e Ambientes Virtuais de Aprendizagem: um estudo sobre o Moodle. Revista de Informática Aplicada, Volume 11, Número 1, 2015.

STURION, L.; REIS, M.C.; FIERLI, A.L. Uma Experiência da Utilização das TICs no Ensino Superior Através de um Sistema Semipresencial. UNOPAR Cient., Ciênc. Human. Educ., Londrina, v. 12, n. 1, p. 31-36, Jun. 2011. 